\title{
Boosted Tree Ensembles for Artificial Intelligence Based Automated Valuation Models (AI-AVM)
}

\author{
Tien Foo Sing ${ }^{1,2} \cdot$ Jesse Jingye Yang $^{2}$. Shi Ming Yu ${ }^{1}$
}

Accepted: 17 August 2021 / Published online: 5 November 2021

(c) The Author(s), under exclusive licence to Springer Science+Business Media, LLC, part of Springer Nature 2021

\begin{abstract}
This paper develops an artificial intelligence based automated valuation model (AIAVM) using the boosting tree ensemble technique to predict housing prices in Singapore. We use more than 300,000 private and public housing transactions in Singapore for the period from 1995 to 2017 in the training of the AI-AVM models. The boosting model is the best predictive model that produce the most robust and accurate predictions for housing prices compared to the decision tree and multiple regression analysis (MRA) models. The boosting AI-AVM models explain $91.33 \%$ and $94.28 \%$ of the price variances, and keep the mean absolute percentage errors at $8.55 \%$ and $5.34 \%$ for the public housing market and the private housing market, respectively. When subject the AI-AVM to the out-of-sample forecasting using the 2018 housing sale samples, the prediction errors remain within a narrow range of between $5 \%$ and $9 \%$.
\end{abstract}

Keywords Automated valuation model $\cdot$ Decision tree $\cdot$ Boosting $\cdot$ Housing markets

We would like to thank National University of Singapore for the research funding supports for the project, and to thank Ying Fan, Xuefeng Zhou, Liu Ee Chia, Namita Dinesh, Poornima Singh, Chun Keat Khor, and others for their research supports and assistance.

Tien Foo Sing

bizstf@nus.edu.sg

Jesse Jingye Yang

jesse@nus.edu.sg

Shi Ming Yu

bizyusm@nus.edu.sg

1 Department of Real Estate, National University of Singapore, Singapore, Singapore

2 Institute of Real Estate and Urban Studies, National University of Singapore, Singapore,

Singapore 


\section{Introduction}

Housing serves the basic need of human beings. It provides not just a shelter over the head, but a place for them to raise their children. Other than meeting the consumption motive, housing is also the single largest asset class of many people, which appreciates in value and provides them with a safety net when they retire.

Buying houses is a complex decision-making process. Buyers will need to determine a reasonable and fair market value for houses before making their purchasing decision (Fisher, 2002). Housing value is a function of a set of hedonic attributes, such as area, floor level, age, land tenure, and neighborhood characteristics and surrounding amenities, such as the distance to the nearest MRT stations, schools, shopping malls, parks and Centre Business District (CBD). Based on comparable housing transactions from the same development and/or neighboring developments, professional appraisers derive at, in their views, a reasonable market value for a subject house after considering all observable attributes. Professional appraisers rely on their experience and knowledge of the local market when making value judgements in the appraisal process.

No two appraiser will ever derive at the same value for a subject property. If deviations in appraised values were caused by information asymmetries between two appraisers, the problem could be mitigated through the use of big data and technology. However, it is harder to resolve differences caused by divergence in opinions of two appraisers with respect to a given set of attributes of the subject and comparable properties.

While licensed appraisers have the obligations to provide unbiased opinions on housing values, they may also in some instances be succumbed to pressures of related parties to bias their appraised values. Appraisal bias that inflates values of residential real estate used as collaterals is not uncommon, where borrowers are motivated to use higher appraisal values to increase the leverage as measured by the loan-to-value ratio of mortgage loans (Agarwal, 2007; Agarwal et al., 2015, 2017; Bogin \& Shui, 2020). It is thus necessary to reduce human errors by strengthening the science in the appraisal process.

Some real estate experts and researches have been advocating more "science" in appraisals through the use of various methodologies ranging from case-based methods to multiple regression analysis (MRA) models and more sophisticated expert systems (O'Roarty et al., 1997; Pagourtzi et al., 2003;). With the advancements in computational sciences, more translational applications of artificial intelligence (AI) and machine learning algorithms, such as support vector machine and artificial neural network (ANN) (Bogin \& Shui, 2020; Chiarazzo et al., 2014; Kok et al., 2017; Peterson \& Flanagan, 2009; Yacim \& Boshoff, 2018) have been explored. However, the adoption of AI in real estate appraisals is still lagging behind and not as prevalent as expected. Skeptics who are apprehensive of the "substitutability" for the art of appraisal have resisted the technological adoption in appraisals (Shiller \& Weiss, 1999).

In the objectives of advancing the "science" and bridging the gap in translational applications of advanced computation tools in real estate appraisals, this 
study develops the AI automated valuation models (AI-AVM) for residential properties using the established approaches, such as decision tree and/or boosting methodologies. There are two unique features of our proposed AI-AVM: First, we use the bagging and boosting method to capture inter-dependency in the decision tree in the ANN model. We also use the one year lagged average housing values at the building level to enhance the time-dependent relationships in values between the comparable and the subject property. The two features improve our model in mimicking the serial-correlation behaviors that are commonly found in the housing markets; and second, we use a large sample of more than 300,000 housing transactions to enhance the training of the ANN models.

We train the proposed AI-AVM models using the historical real estate sale data in Singapore from 1995 to 2017 and conduct forecasting tests using the 2018 transactions from the same market as the out-of-the-box (OOB) samples. Our results show that the proposed AI models (i.e. tree-based model with boosting) outperform the traditional MRA model using various predictive error measures. We show that the boosting method in the AI-AVM produces the best prediction among the three methods. The boosting technique also produces slightly better predictive outcomes for the more homogenous public (HDB) housing market compared to the model for the private housing market.

After laying the motivations of the study, the remainder of the paper is organized as follows: Section 2 reviews the relevant literature; Section 3 gives a brief overview of the artificial neural network (ANN) and artificial intelligence (AI) system; Section 4 discusses our proposed AI-AVM models based on the decision tree and boosting method; Section 5 illustrates how the proposed models are applied to predict housing transaction prices in Singapore; Section 6 concludes by highlighting potential applications and limitations of the models.

\section{Literature Review}

The "Computerised Assisted Assessment" (CAA) system was developed in 1970s and applied by local authorities to improve efficiency and reduce subjectivity in land appraisals. The CAA concept was then built into various statistical-based models, such as "Computer Assisted Mass Appraisal (CAMA)" and "Automated Valuation Model (AVM)", and were applied to the broader property appraisals (Kindt \& Metzner, 2019).

Interests in ANN and AVM applications emerged in the real estate literature in the 1990s and early 2000s (Lenk et al., 1997; McCluskey et al., 1997; McGreal et al., 1998; Nguyen \& Cripps, 2001; Tay \& Ho, 1992; Tsukuda \& Baba, 1994; Worzala et al., 1995). The early ANN-AVM systems were built on the back-propagation model and trained using a small dataset of residential property sales. Many early studies found that the performance of the early version of ANN models was unsatisfactory (Lenk et al., 1997 and Worzala et al., 1995).

The ANN models are not bounded by the normality assumptions. By having multiple layers of perceptions, the models allow complex nonlinearities; and the newer version of ANN models significantly improve reliability and accuracy when used to 
predict residential property values. (Bogin \& Shui, 2020; Kok et al., 2017; Nguyen \& Cripps, 2001; Peterson \& Flanagan, 2009; Yacim \& Boshoff, 2018).

As technology advances, complex ANN models, such as Adaptive Neuro-Fuzzy inference System (ANFIS) (Guan et al., 2008); radial basis function neural networks (RBFNN) and memory-based reasoning (MBR) models (Zurada et al., 2011) have been developed. Integrating other AI and ANN technologies, such fuzzy logic (Guan et al., 2008), neuro-fuzzy, genetic algorithm and expert system are expected to become key future research agenda (Clapp, 2003). Some of these advanced ANN algorithms have been applied in real estate fields. For example, Gongzlez and Formoso (2006) and Sing et al. (2002) illustrate how fuzzy logic could be applied for real estate appraisals and investment analyses.

\section{Limitations of the ANN-AVM Models}

The ANN model has its advantages, which include defensible against the accusations of subjectivity in valuation and cost savings. ANN is, however, not a substitute to the "art" aspect in the appraisal. Appraisers' experience and knowledge in adjudicating the fair and reasonable values are still necessary in the appraisal process (Ibrahim et al., 2005; Zurada et al., 2011).

There are limitations to AI-ANN models. First, the most common criticism is the "black box" nature of the models. The AI-ANN models are developed to mimic the human brain that learns via "repetitions of similar stimuli" by pairing historical input and output data. The internal structure connecting various nodes in the models is usually not known, and thus the process is accused to be a "black box". Unlike the MRA models that provides causal relationships between the predictors and the outcome, the AI-ANN models are opaque and lack the interpretable feature of the MRA models. At the expense of interpretability, the black-box model however, has superior predictability performance compared to other structures and interpretable models, such as MRA.

Second, AI-ANN models require a large sample of data to train and improve the model's accuracy in predicting property values. When applied to an illiquid market with sparse transaction data, there is a risk that a model could either be over-trained or under-trained; and as a result, the model is likely to generate poor outputs (Worzala et al., 1995; McGreal et al., 1998; Lam et al., 2008; Zurada et al., 2011).

The downside of being a black-box is that it is hard to detect problems, such as over-fitting and spurious correlations and others, which subject the models to the "garbage in - garbage out" dilemma. The black-box models are not designed to deal with exogenous shock / outliers that are not observed in the training dataset. In this study, we deal with the black box problems in three ways: First, by using the bagging and boosting methods, we could reduce overfitting problems through a sequential and repeated learning process; second, the feature importance function in the boosting method provides some explanations of different variables' contributions to predictive outcomes (see Figs. 10 and 11); and third, by using a large sample of input data that span across 22 years covering three major crises in the markets (Asian Financial Crisis in 1997; Severe Acute Respiratory Syndrome (SARS) 

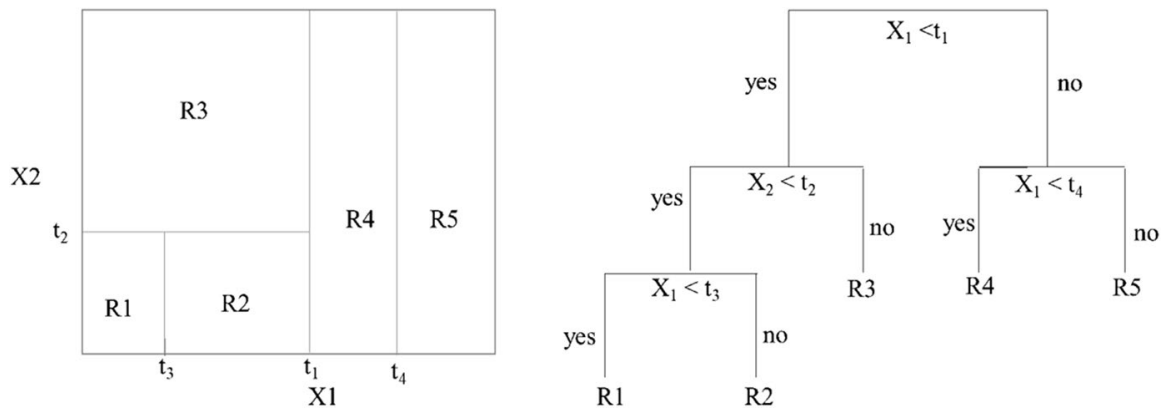

Fig. 1 The decision tree method. Note: The figure shows the decision tree classification methodology. The left hand figure shows how the space is divided based on two predictors, $\left[\mathrm{X}_{1}, \mathrm{X}_{2}\right]$, into 5 distinct regions, $\left[R_{1}, R_{2}, R_{3}, R_{4}, R_{5}\right]$. The right hand figure shows the same classification outcome but using the tree representation, which include branches and terminal nodes

outbreak in 2003 and Subprime Crisis in 2007), the model is adequately trained to deal with potential shock within a reasonable range.

\section{The Proposed AI-AVM Structure}

We proposed the tree-based AI-AVM model, which is developed using the decision tree ensembles and boosting techniques. A decision tree is a set of splitting rules that is used to segment predictor space. A single decision tree alone is simple and easy to interpret; but by itself, the decision tree is less popular because of its poor predictive accuracy. More advanced ensemble methods, such as bagging and boosting, ${ }^{1}$ are used in this study to improve the predictive accuracy by combining a large number of trees into the models (James et al., 2013) (Fig. 1).

\section{Decision Trees}

A decision tree is technically made up of multiple strands of splitting rules starting from the top of the tree. There are two types of decision trees, which are a regression tree and a classification tree. A regression tree for a real estate price is represented by a continuous outcome variable, $\mathrm{Y}$, and multiple inputs, $\left[\mathrm{X}_{1}, \mathrm{X}_{2}, \ldots\right]$. The left-hand panel of Fig. 2 shows how the response $\mathrm{Y}$ can be divided by different responses (attributes) into five different regions, $\left[\mathrm{R}_{1}, \mathrm{R}_{2}, \mathrm{R}_{3}, \mathrm{R}_{4}, \mathrm{R}_{5}\right]$. The $\mathrm{Y}$ space can be partitioned at the mean (or proportion) of each of the response, $\left(x_{i}, y_{i}\right)$, into two regions, where each vertical column represents different splitting rules.

\footnotetext{
${ }^{1}$ Random forest is another popular ensemble method, which follows the same bootstrapping process like the bagging method, but it limits the split using a random subset of variables usually from the spatial and property attributes. However, our study uses the boosting method, which uses a sequential iteration approach to correct time-dependent errors, especially those caused by the weak learners in the process.
} 


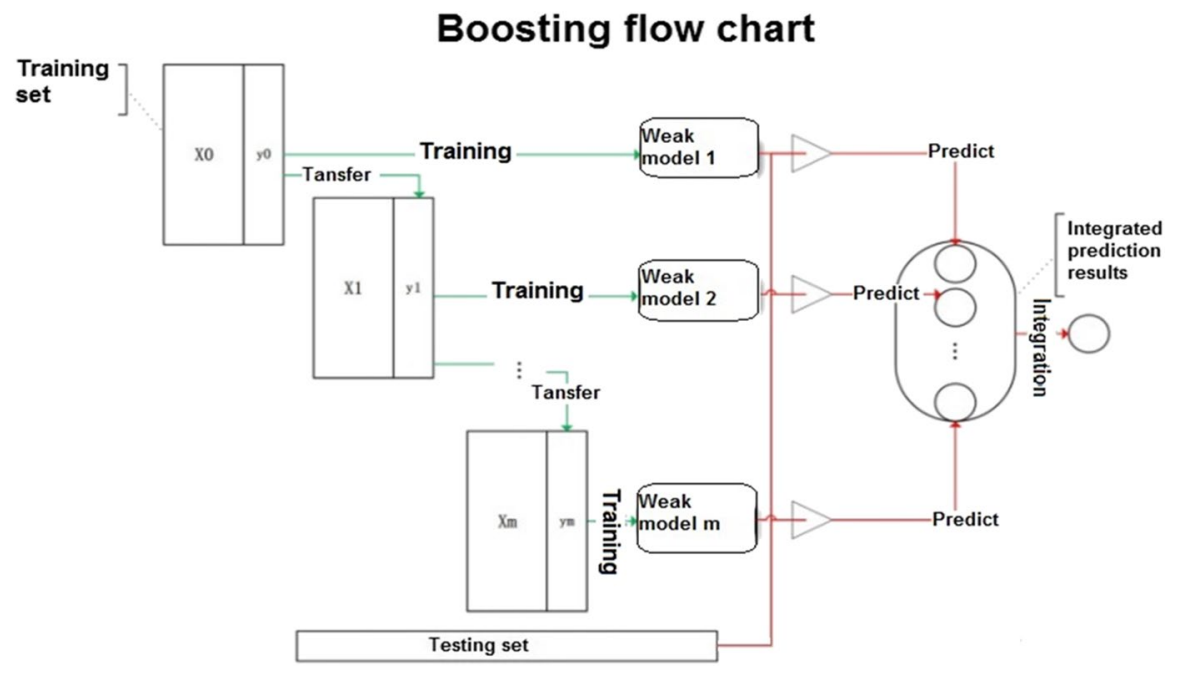

Fig. 2 The in-house designed Boosting Model. Note: The figure shows the flow chart of the boosting ensemble method, which sequentially identifies the "weak learners" and corrects the errors to change the weak learners into strong learners

The right-hand panel of Fig. 2 uses an inverted tree representation for the decision tree, where the splitting starts from the root at the top and moves downward sequentially. The first split is at the region $\left[\mathrm{X}_{1}=\mathrm{t}_{1}\right]$ into two branches, one is defined by $\left[\mathrm{X}_{1} \leq \mathrm{t}_{1}\right]$ and another by $\left[\mathrm{X}_{1}>\mathrm{t}_{1}\right]$; and then the left-hand branch, $\left[\mathrm{X}_{1} \leq \mathrm{t}_{1}\right]$, is further split at the region, $\left[\mathrm{X}_{2}=\mathrm{t}_{2}\right]$. For the right-hand branch, $\left[\mathrm{X}_{1}>\mathrm{t}_{1}\right]$, the split occurs at $\left[\mathrm{X}_{1}=\mathrm{t}_{3}\right]$; and then the branch, $\left[\mathrm{X}_{1}>\mathrm{t}_{3}\right]$ is further split at $\left[\mathrm{X}_{2}=\mathrm{t}_{4}\right]$. The splitting process continues till some stopping rules are applied.

For a response, $\left(x_{i}, y_{i}\right)$, such that $[\mathrm{i}=1,2, \ldots \mathrm{p}]$, where $\mathrm{p}$ denotes the number of observations (inputs), the split variables and the split points are automatically decided by the algorithm that defines a tree topology. The feature space is divided into $M$ regions by several rules (constants), $\left[R_{1}, R_{2}, \ldots, R_{M}\right]$, which can be defined as follows:

$$
f(x)=\sum_{m=1}^{M} c_{m} I\left(x \in R_{m}\right)
$$

The decision tree mimics closely the way a human makes decisions, which are sometimes represented by qualitative predictors. Decision trees use a simple to interpret graphical representation, but the prediction of a decision tree is not as stable as the regression models. A small change in data could cause a big change in outcomes. To overcome the limitations, two ensemble methods that are bagging and boosting are used in this study to aggregate multiple decision trees. However, a large ensemble of decision trees could potentially increase computational time, especially when the dataset used is also large. 


\section{Tree Ensemble Methods: Bagging and Boosting}

One major limitation of the decision tree method is the high variance in outcomes. When we divide the data into a training dataset and a testing dataset, we may obtain different results every time when we fit a decision tree to different datasets. There are various ensemble approaches used to reduce variances in the outcomes. This study uses bagging and boosting methods, where the boosting is a relatively more efficient method in term of computational time (see the next section for details).

Bagging uses the bootstrap method to first generate $B$ sets of different bootstrapped training data repetitively from a single training data set. After building a separate decision tree from the $B$ training data sets, the next step in the bagging process is to average the sets of observations to reduce variances, and in turn increase accuracy in prediction.

In bagging, each tree is built on a bootstrapping data set that is independent of other trees. However, in boosting method, the trees are grown sequentially from the previous trees. The trees constructed by the boosting method is strongly dependent on the earlier trees that have been grown. ${ }^{2}$ The output of the boosting model can be formulated as below:

$$
\hat{f}(x)=\sum_{b=1}^{B} \lambda \hat{f^{b}}(x)
$$

where $b$ is the number of repetitive times from 1 to $\mathrm{B}$, and $\lambda$ is the shrinkage parameter with a typical value set at between 0.01 and 0.001 .

\section{Estimating Procedures}

Based on the proposed tree-based model, we compute the original residual, which is defined as the difference between the actual housing value (dependent variable) and the predicted housing value. The "weak learners", which are assigned more weights based on the residual errors. The boosting method repeatedly and sequentially corrects and fits the residuals of "weak learners" by the predecessors in a bootstrapping process. The boosting method reduces variance and bias in the tree ensemble by converting "weak learners" into "strong learners" in the process.

We start by building a small decision tree with just a few terminal nodes. We expand and add new trees to the ensemble of trees that have already been grown. We improve the performance of the small tree steps by steps by reducing the shrinkage parameters.

Three parameters are used to measure the efficacy and the speed of the learning process. The first parameter is the number of trees $B$, where a large $B$ indicates positive performance of the decision trees. However, the optimal $B$ must be carefully selected through a cross-validation process to avoid overfitting of the model, which

\footnotetext{
2 The trees in the boosting method are path dependence by nature (Ruppert, 2004), and this is an important feature widely observed in real estate appraisals. More discussions are included in the next section.
} 
occurs by having a very large $B$. The second parameter is the shrinkage parameter, $\lambda$, which controls the rate of the boosting in the learning process; and this number typically falls within a small range between 0.01 and 0.001 . A good model should have a very small $\lambda$ and a large $B$. The third parameter $d$ is the number of splits in each tree that defines the interaction order of the boosting model. A model with a large $d$ has a more complex boosted tree structure with the required depth in interactions.

In the boosting model, a loss function is selected as the optimization target by a stepwise optimizing algorithms for a typical regression tree, which are defined below:

1. Set $\hat{f}(x)=0$ and $r_{i}=y_{i}$ for all $i$ in the training set.

2. For $b=1,2, \ldots, B$, repeat:

a. Fit a tree $\hat{f}^{b}$ with $d$ splits $(d+1$ terminal nodes) to the training data $(X, r)$.

b. Update $\hat{f}$ by adding in a shrunken version of the new tree:

$$
\hat{f}(x) \leftarrow \hat{f}(x)+\lambda \hat{f}^{b}(x) .
$$

c. Update the residuals,

$$
r_{i} \leftarrow r_{i}-\lambda \hat{f}^{b}\left(x_{i}\right)
$$

\section{Output the Boosted Model}

$$
\hat{f}(x)=\sum_{b=1}^{B} \lambda \hat{f}^{b}(x) .
$$

Figure 2 shows the flowchart of the Boosting algorithms, which can be broadly divided into the following steps:

1. To train a weak classifier using the training dataset;

2. To adjust training dataset to allow conversion of the weak classifier using a predefined strategy;

3. To repeat the training of other weak classifiers using the same approach (can be done in parallel distributed computational process). All weak classifiers in the boosting can be different;

4. To combine the weak classifiers obtained from the previous training to form a strong classifier; and

5. To improve the accuracy of a given learning algorithm.

\section{Predictive Performance Measures}

A "horserace" can be conducted for the tree-based AI-AVM models that account for non-linearity in the predictive relationships against the traditional multiple regression (MRA) models. We assess the predictive performance of the proposed AI-AVM 
and MRA models using three performance measures, which include $\mathrm{R}^{2}$, Root mean square error (RMSE) and Mean absolute percentage error (MAPE).

Let $y_{i}$ and $\hat{y}_{i}$ represent the actual housing price and the predicted price, respectively. The absolute error is defined:

$$
e_{i}=\left|y_{i}-\hat{y}_{i}\right|
$$

The R-square, $\left(\mathrm{R}^{2}\right)$, which is also known as coefficient of determination, with a value bounded between 0 and 1 is defined in percentage term as:

$$
R^{2}=1-\frac{\sum_{i=1}^{N}\left(y_{i}-\hat{y}_{i}\right)^{2}}{\sum_{i=1}^{N}\left(y_{i}-\overline{y_{i}}\right)^{2}}
$$

where $\overline{y_{i}}$ is the mean housing price, and $\mathrm{N}$ is the number of cases.

The root means square error, (RMSE) is defined as:

$$
R M S E=\sqrt{\frac{1}{N} \sum_{i=1}^{N}\left(y_{i}-\hat{y}_{i}\right)^{2}}
$$

The scaled mean absolute percentage error (MAPE) is defined as:

$$
M A P E=\frac{100 \%}{N} \times \sum_{i=1}^{N}\left|\frac{\left(y_{i}-\hat{y}_{i}\right)}{y_{i}}\right|
$$

$\mathrm{R}^{2}$ measures variance in a dependent variable that is accounted for by predictors in the model; and a better performed model should have a higher $\mathrm{R}^{2}$ value. However, a smaller value for RMSE and MAPE implies more accurate predictions.

By randomly splitting the data into a training dataset and a test dataset, we repeat the estimations by 50 times for each training-test split set to enable the convergence in the prediction accuracy. We derive the three indices for each of the random iteration and then calculate the average $\mathrm{R}^{2}$, RMSE and MAPE as the model's prediction performance measures.

\section{Applications of the Proposed AI-AVM}

This sections illustrates how the proposed AI-AVM developed using the decision tree and boosting technique is applied to appraise private and public housing values in Singapore.

\section{Housing Markets in Singapore}

Singapore has one of the highest home ownership rates in the world. Every nine in 10 public housing dwellers own their flats in Singapore as of 2020. The Home Ownership Scheme introduced in 1964 has been one of the key pillars underpinning 
Singapore's public housing system, which is enviable to many countries facing acute housing shortage problems.

Singapore housing market is characterized by a two-tier housing market comprising a public market and a private market. The public housing market forms a rocksolid base where nearly 1.08 million public housing flats currently serves the housing needs of more than $78 \%$ of Singapore residents. Public housing flats provide new starter houses at subsidized rates for first time home buyers, who meet specified social, demographic and income criteria. ${ }^{3}$ There is a formal resale market for public housing units, where prices are market determined. The public housing wealth can only be cashed out by the households upon satisfying a 5-year minimum occupancy requirement. The difference in price between the new and resale public housing markets creates housing wealth to the first-time home buyers. The financial gains from selling the starter houses provide an important source of funding for down payments for liquidity constrained households in trading-up for private (trade-up) houses.

The private housing market in Singapore operates on a laissez faire basis. Private housing units are more expensive. They are also differentiated by better designs, quality of finishes, and some (condominiums and apartments) are equipped with full recreational facilities. Despite the relatively small scale of the private housing market, housing types are more heterogeneous and range from landed units like detached houses, semi-detached houses and terraces to non-landed units like condominiums and apartments.

\section{Input Data and Variables}

The preliminary steps in estimating the AI-AVM model involve data collection, cleaning and coding of input variables. We collect a big dataset consisting of 378,032 transactions from both the private and the public (resale) housing markets in Singapore covering the period from 1995 to 2019. We drop observations with incomplete and missing data, and truncate $1 \%$ of the samples at both tails of the distributions to eliminate outliers. We then split the dataset into a training dataset and a testing dataset by a ratio of 9:1. The data analyses are conducted using the algorithms written in the $\mathrm{R}$ program.

In addition to the transaction unit price, which is the dependent variable of the model, the data include a list of hedonic property and spatial attributes, such as unit size, floor level, tenure, sale type, project name and sale date, which are used as the predictors in the proposed AI-AVM model. Table 1 describes the list of variables.

\section{Adjusting for Lagged Price Effects}

Appraisers use past transactions as comparable in the price adjustment process. When the appraised values are closely anchored to the past reference point,

\footnotetext{
3 See Phang (2004) and Sing et al. (2006) for detailed discussions of policy changes affecting the public housing market in Singapore over time.
} 
Table 1 Description of variables

\begin{tabular}{|c|c|}
\hline Variable & Description \\
\hline \multicolumn{2}{|c|}{ (A) For private housing model } \\
\hline Uprice & transacted unit price (S\$ per square meter); \\
\hline Floor & Floor level (height) of property (storey); \\
\hline Area & Unit size (square meters, sm); \\
\hline Month & The month in the transaction date, $[1,2, \ldots 12]$ \\
\hline Year & The year of the transaction, [1995 to 2019]; \\
\hline Freehold & $\begin{array}{l}\text { Land tenure that has a value of } 1 \text {, if it is a freehold land and a leasehold } \\
\text { land of more than } 900 \text { years; and otherwise } 0 \text {; (only for private hous- } \\
\text { ing) }\end{array}$ \\
\hline Dist_city & Distance to the CBD $(\mathrm{km})$ \\
\hline Dist_MRT & Distance to the nearest MRT station (in km); \\
\hline Рyp & $\begin{array}{l}\text { The average transaction unit price of the same project in the previous } \\
\text { one year (S\$ per square meter) }\end{array}$ \\
\hline \multicolumn{2}{|c|}{ (B) For Public Housing model } \\
\hline Uprice & transacted unit price (S\$ per square meter); \\
\hline Floor & Floor level (height) of property (in storey); \\
\hline Area & Unit size (square meters, sm); \\
\hline Month & The month in the transaction date, $[1,2, \ldots 12]$; \\
\hline Year & The year of the transaction, [1995 to 2019]; \\
\hline Dist_city & Distance to the CBD $(\mathrm{km})$ \\
\hline Dist_MRT & Distance to the nearest MRT station (in $\mathrm{km}$ ); \\
\hline Pyp & $\begin{array}{l}\text { The average transaction unit price of the same project in the previous } \\
\text { one year ( } \mathrm{S} \$ \text { per square meter) }\end{array}$ \\
\hline
\end{tabular}

Note: The table summarizes a list of variables with the descriptions that are used in constructing the housing price models using the decision-tree, boosting and multivariate regression analysis (MRA) methods. The top panel includes the variables from the private housing market, and the bottom panel includes variables from the public housing market. The freehold dummy variable is only found in the top panel, which has a value of 1, if a land has freehold tenure or leasehold tenure of more than 900 years; and 0 otherwise. The dummy is not used in the public housing market, which has the same 99-year leasehold tenure

appraised values could be out-of-sync with market prices in both up and down-markets (Fisher et al., 1999). The price index constructed from appraised values of a fixed portfolio of real estate tend to understate the true market volatility and exhibit strong lagged-relationships; and the problem is commonly known as "appraisal smoothing" in the literature (Geltner, 1989). Geltner (1989, 1991), Quan and Quigley (1991) and other researchers have proposed ways to "unsmooth" (de-lag) the appraisal-based indices to uncover the "true" real estate return. The approach adds serial-correlations (lagged auto-regressive term) back to the appraisal-based returns to infer the true returns.

In an inefficient housing market, serial correlations could also exist in prices because of the slow price discovery process. Case and Shiller (1980 and Case \& Shiller, 1990) found evidence of correlated real price changes in the short-term using repeated 
Table 2 Descriptive Statistics

\begin{tabular}{|c|c|c|c|c|c|}
\hline & variable & mean & $\min$ & $\max$ & SD \\
\hline \multicolumn{6}{|l|}{ (A) Public Housing Market } \\
\hline Unit Price (S\$ psm) & uprice & 3288.71 & 1963.41 & 5462.69 & 927.33 \\
\hline Floor level (storey) & floor & 7.5 & 2 & 38 & 4.41 \\
\hline Unit area $(\mathrm{sqm})$ & area & 96.93 & 31 & 280 & 25.25 \\
\hline Building age (year) & age & 29.49 & 5 & 52 & 9.33 \\
\hline Year of sale & year & 2007.97 & 2001 & 2017 & 4.57 \\
\hline Month of Sale & month & 6.46 & 1 & 12 & 3.4 \\
\hline Distance to the nearest MRT station $(\mathrm{km})$ & dist_MRT & 0.7 & 0.01 & 2.81 & 0.46 \\
\hline Distance to CBD (km) & dist_city & 11.6 & 1.4 & 18.4 & 3.86 \\
\hline Previous year unit $(\mathrm{S} \$ \mathrm{psm})$ price & Pyp & 3168.5 & 1963.77 & 5462.69 & 866.05 \\
\hline \multicolumn{6}{|l|}{ (B) Private Housing Market } \\
\hline Unit Price $(\mathrm{S} \$ \mathrm{psm})$ & uprice & 9655.64 & 3965.52 & $27,133.33$ & 3720.12 \\
\hline Floor level (storey) & floor & 8.36 & 1 & 66 & 6.78 \\
\hline Unit area (sqm) & area & 126.22 & 24 & 1212 & 53.26 \\
\hline Building age (year) & age & 10.73 & 1 & 64 & 7.29 \\
\hline Freehold tenure dummy & freehold & 0.49 & 0 & 1 & 0.5 \\
\hline Year of sale & year & 2009.56 & 1996 & 2019 & 5.65 \\
\hline Month of Sale & month & 6.22 & 1 & 12 & 3.18 \\
\hline Distance to the nearest MRT station $(\mathrm{km})$ & dist_MRT & 1.09 & 0.03 & 5.75 & 0.78 \\
\hline Distance to CBD (km) & dist_city & 7.3 & 0.4 & 24.4 & 3.9 \\
\hline Previous year unit (S\$psm) price & Pyp & 9051.13 & 3965.52 & $19,658.11$ & 3601.59 \\
\hline
\end{tabular}

Note: The table provides the summary statistics, which include the mean, minimum, maximum and standard deviation (SD) for the list of the outcome variables and predictors. The top panel (A) shows the results for the private housing market, and the bottom panel (B) shows the results for the public housing market

transactions in the single-family housing markets in the selected US cities. The two strands of literature are not mutually exclusive; it is difficult to disentangle serial correlations (appraisal smoothing) in the transaction prices and appraised values. However, it is not the intent of our study to separate serial correlations in our model; instead, recognizing the inefficiency in the housing markets, our AI-AVM models incorporate the lagged price variable, which is the average transaction prices at the project level in the previous year, to improve the predictability of housing prices. ${ }^{4}$

\section{Descriptive Statistics}

Table 2 shows the descriptive statistics of mean, minimum, maximum, and standard deviation of both the dependent variable and independent variables used in the

\footnotetext{
4 The feature importance analysis in Section 4.5 shows that the lagged price variable appears to be the most influential factors in predicting housing prices in the private and public housing markets.
} 
models. The summary statistics are presented separately for the private and the public housing markets.

The public (resale) housing market is a regulated market that provides affordable housing flats to Singaporean residents. The average unit price of public housing flats is lower estimated at $\mathrm{S} \$ 3289$ per square meter ( $\mathrm{psm}$ ) compared to private apartments and condominiums in Singapore, where were transacted at an average price of $\mathrm{S} \$ 9656 \mathrm{psm}$. The one-year lagged average unit prices are lower at $\mathrm{S} \$ 3169 \mathrm{psm}$ and $\mathrm{S} \$ 9051 \mathrm{psm}$ in the public and private housing markets, respectively.

In the land scarce Singapore, high-rise high-density living is prevalent in both private and public housing markets. The average floor level (height) of housing units transacted in the public housing and private housing markets are 8.36 storey and 7.5 storey, respectively. By the unit size, private apartments and condominiums are relatively larger with an average gross floor area of 126.22 square meter (sqm) compared to the average floor area of 96.93 sqm for public housing flats. The public housing samples are older with an average age of 29.49 years compared to the average age of 10.73 years for the private housing samples. While all the public housing flats are sold on the leasehold tenure; nearly half of the private apartments and condominiums have a freehold tenure.

Private apartments and condominiums are located closer to the central business district (CBD) with an average distance of $7.3 \mathrm{~km}(\mathrm{~km})$ compared to the public housing flats with an average distance to CBD of $11.6 \mathrm{~km}$. Private apartments and public housing flats are well connected to the public transport network with the average distances to the nearest MRT stations estimated at $1.09 \mathrm{~km}$ and $0.7 \mathrm{~km}$, respectively.

\section{Univariate Analyses}

Prior to fitting the data to the proposed AI-AVM model, we run the univariate analyses on the relationships between the predictors and the property prices, which are the outcome variables. Figures 3 and 4 show the line plots of the relationship between the continuous predictors and the property prices for the private and the public (HDB) housing markets, respectively. Figure 4 also includes a box plot that represent the relationship between the categorical predictor (the freehold dummy) and the property prices. The red line in the line plots shows the linear fits of continuous data, whereas the blue line shows the actual lines for the data. For the box plots of categorical data, the vertical dots show the distribution of the observations.

The line plots show the univariate relationships between the predictors and the outcome variables are significantly non-linear for both the private and public housing markets. The two spatial variables, which are the distances to the closest MRT and CBD, shows negative relationships with property prices, but the relationships are non-linear. For the property attributes, such as unit size and floor level, the univariate relationships with prices are not just non-linear but also complex in both the private and the public housing markets. The year and the month of sale plots show irregular and seasonal fluctuations in price trends. The complex relationships are difficult to be directly estimated in the standard MRA estimator. 

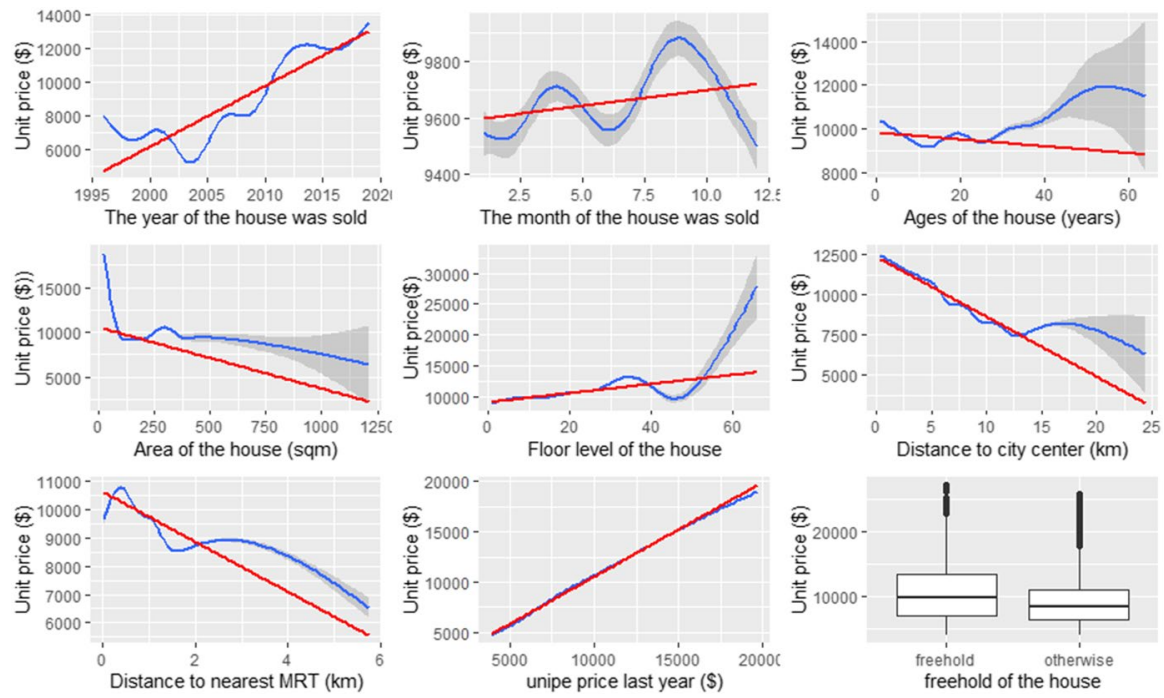

Fig. 3 Univariate Plots of Response and Predictors for Private Housing Market. Note: The figure shows univariate analyses of the relationships between unit price and different predictors. The red lines show the linear fits of continuous data, whereas the blue lines show the actual lines for the data. The last pane is the box plots for categorical data (the freehold dummy), the vertical dots show the distribution of the observations
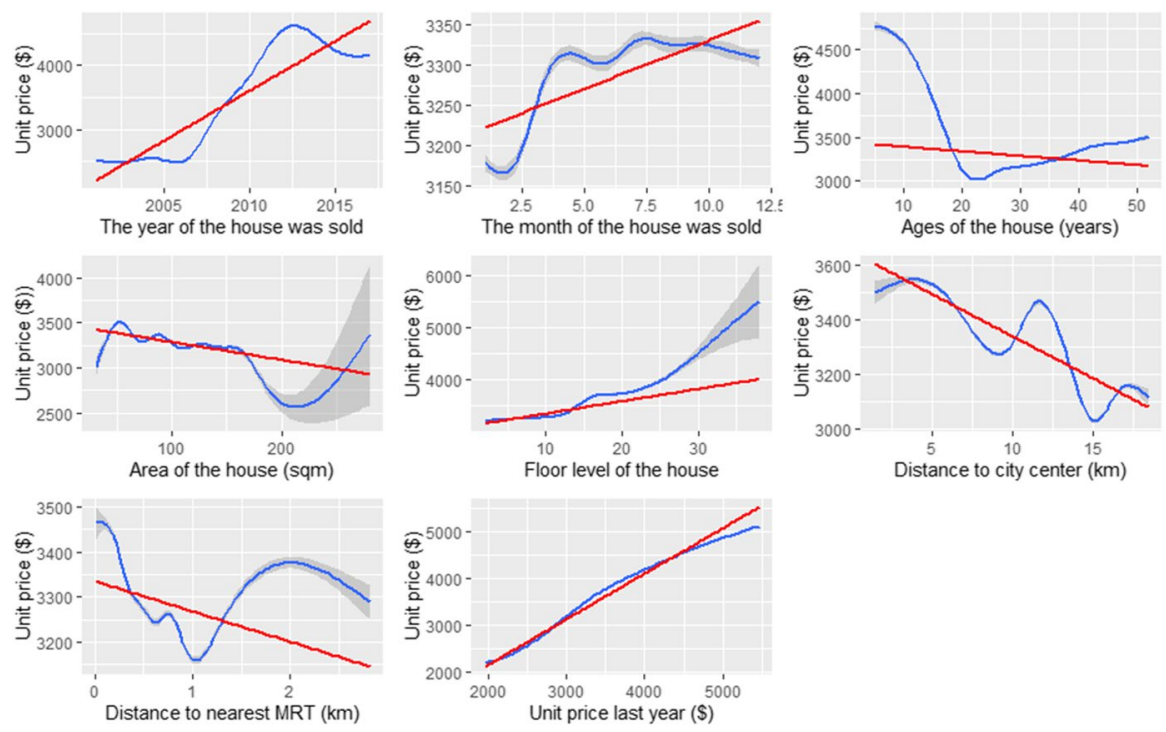

Fig. 4 Univariate Analyses of Response and Predictors for Public Housing Market. Note: The figure shows univariate analyses of the relationships between unit price and different predictors. The red lines show the linear fits of continuous data, whereas the blue lines show the actual lines for the data 


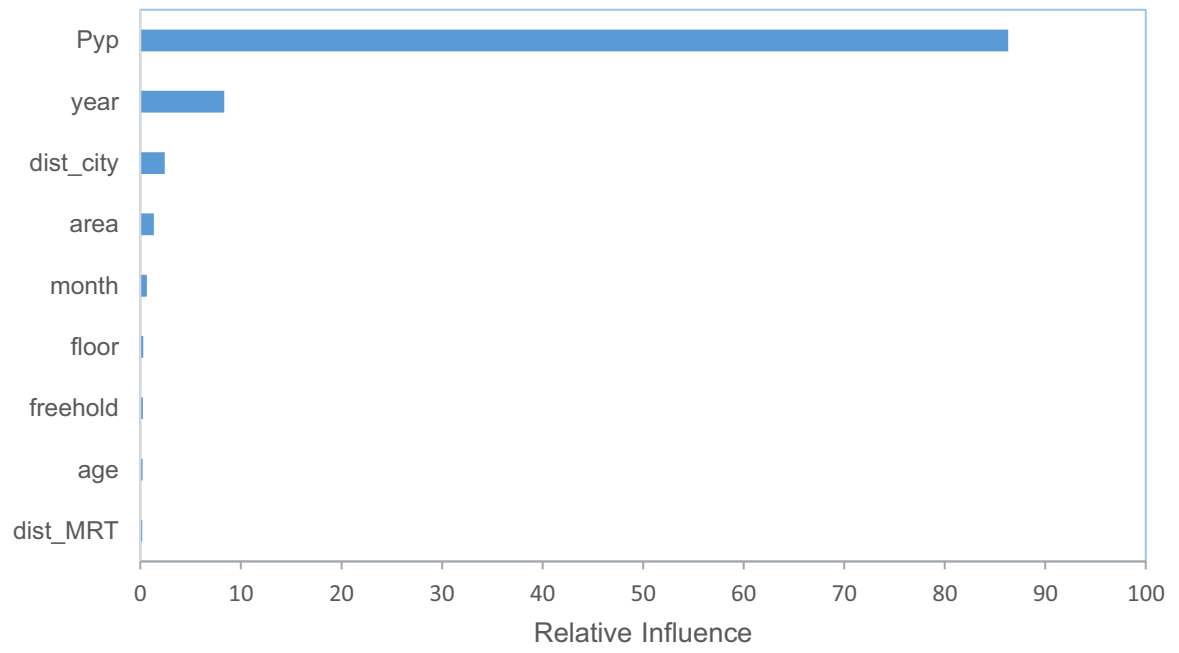

Fig. 5 Important Predictors for Private Housing Price. Note: The figure summarizes the variable importance of predictors for the private housing prices using the boosting method. The details of variables are summarized in Table 1. The relative influence of each of the variable is represented by the horizontal bar, which has a value in the range from 0 to 100

The $A I-A V M$ method has the advantage of fitting the complex relationships and non-linear price trends. The $A I-A V M$ data fitting process does not have to follow the strict assumptions as in MRA, such as independent and identical distributed (i.i.d.) error terms. The models could accommodate abrupt price swings from an increasing trend to a decreasing trend, when the value of an independent variable changes within a certain range.

\section{Predictive Tests of the AI-AVM}

We first run two separate MRA models, one for the public housing market and another one for the private housing markets, using the price responses and the predictor variables as described in Table 1. We then estimate the AI-AVM using the Decision Tree and the Boosting Methods with the same dataset and separately for the private and the public housing markets in Singapore.

In the variable importance analyses in Figs. 5 and 6, the historical price variable, (Pyp), which is the average transaction unit price of the same project in the previous one year, the year dummy, (year), and the spatial variable, (distance to CBD), are the top three most important predictors in the AI-based model for both the private and public (HDB) housing markets. The lagged price variable contributes more than $80 \%$ in the private housing model, and nearly $70 \%$ in the public housing model in predicting the price outcomes. The results shows significant serial correlations in the short term price changes in the two markets, which are consistent the evidence shown in the single-family housing markets in the US (Case \& Shiller, 1989, 1990). 


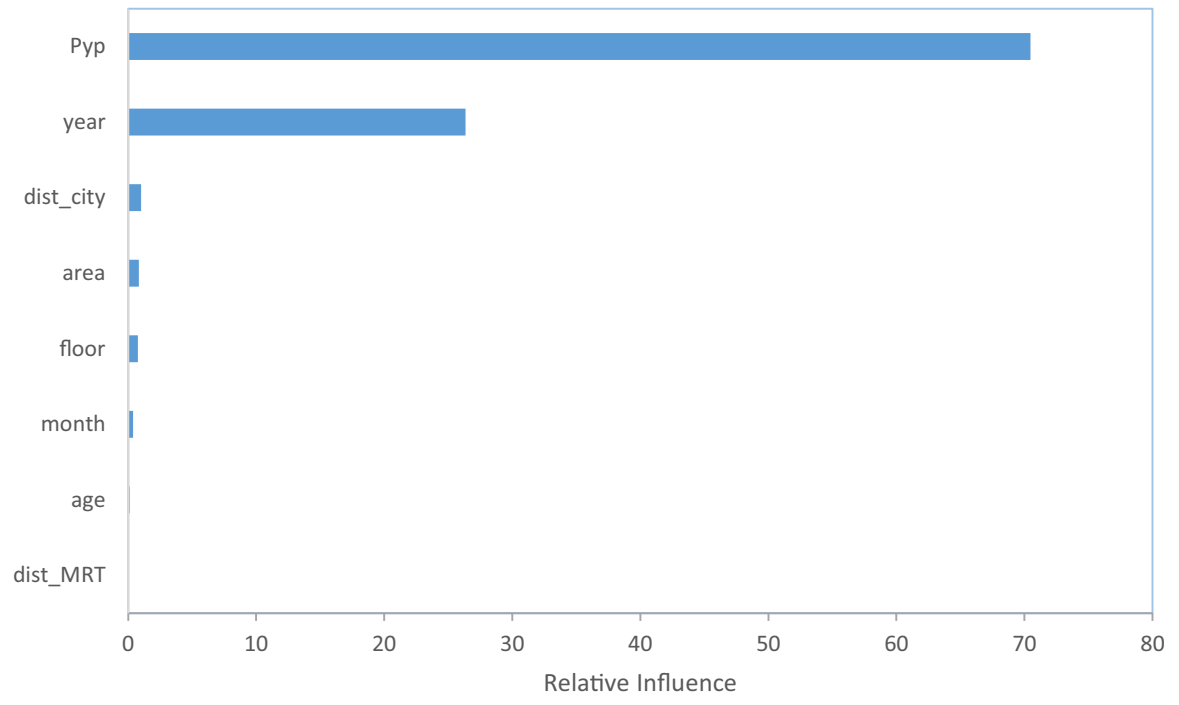

Fig. 6 Important Predictors for Public housing price. Note: The figure summarizes the variable importance of predictors for the public housing prices using the boosting method. The details of variables are summarized in Table 1. The relative influence of each of the variable is represented by the horizontal bar, which has a value in the range from 0 to 100

Other variables, such as unit size (area), floor level and month dummy, have relatively less important weights in the model in predicting property prices. The factors, such as building age and distance to the nearest MRT station, are not critical in predicting both the private and public housing prices in the boosting model.

For the purposes of evaluating the predictive performance of the three model (MRA, Decision Tree and Boosting), a simple "pseudo-horserace" is conducted based on residuals of the predictive outcomes. Table 3 shows the results of the predictive accuracy of the three methods when estimating the private and public properties values, respectively. The results are divided into two parts: (1) the left-hand panel shows the results based on the training dataset, and (2) the right-hand panel shows the results based on the testing dataset.

The top panel of Table 3 shows the performance of the models in predicting private property prices. The results based on the training dataset show that the MRA model predicts about $83.38 \%$ variance of the unit property price with the root mean square error (RMSE) of $\$ 1482.05$, and the mean absolute percentage error (MAPE) of $12.46 \%$. The decision tree method that accounts for $79.63 \%$ variances in unit property prices with the RMSE of $\$ 1640.96$, and MAPE of $13.84 \%$ show weaker predictive accuracy compared to the MRA model.

For the boosting based decision tree model, the $\mathrm{R}^{2}$ is the highest at $91.33 \%$, and the RMSE of $\$ 1070.86$ and the MAPE of $8.55 \%$ are the smallest among the three models. The results imply that the AI-AVM based on the boosting method is the best performer in the predictive tests, and it outperforms the traditional MRA and the decision tree models. The same results were observed when the predictive tests were conducted using the testing dataset. 
Table 3 Prediction accuracy of three methods

\begin{tabular}{|c|c|c|c|c|c|c|}
\hline \multirow[t]{2}{*}{ Model } & \multicolumn{3}{|c|}{ Training Dataset } & \multicolumn{3}{|c|}{ Testing dataset } \\
\hline & $\mathrm{R}^{2}$ & RMSE & MAPE & $\mathrm{R}^{2}$ & RMSE & MAPE \\
\hline \multicolumn{7}{|c|}{ A) Private Housing Market } \\
\hline MRA & $83.38 \%$ & 1482.05 & $12.46 \%$ & $83.38 \%$ & 1482.31 & $12.47 \%$ \\
\hline Decision Tree & $79.63 \%$ & 1640.96 & $13.84 \%$ & $79.56 \%$ & 1643.90 & $13.86 \%$ \\
\hline Boosting & $91.33 \%$ & 1070.86 & $8.55 \%$ & $91.12 \%$ & 1083.96 & $8.64 \%$ \\
\hline \multicolumn{7}{|c|}{ B) Public Housing Market } \\
\hline MRA & $86.86 \%$ & 334.51 & $8.06 \%$ & $86.87 \%$ & 334.34 & $8.06 \%$ \\
\hline Decision Tree & $84.28 \%$ & 365.86 & $8.82 \%$ & $84.27 \%$ & 365.98 & $8.82 \%$ \\
\hline Boosting & $94.28 \%$ & 220.71 & $5.30 \%$ & $94.25 \%$ & 221.22 & $5.31 \%$ \\
\hline
\end{tabular}

Note: The table compares the predictive performance of the three models, which include multivariate regression analysis (MRA), decision tree, and boosting models. Three performance measures are used in the table, which include R-square (R2), root mean squared error (RMSE), and mean absolute percentage error (MSPE). The top panel shows the results for the private housing market, and the bottom panel shows the results for the public housing market. The performance tests are also conducted using two different datasets, which include the training (left panel) and the testing (right panel) datasets

The bottom panel of Table 3 shows the predictive test results for the public housing market. Based on the train dataset, the results show that the MRA model predicts $86.86 \%$ of the variance in public property prices, with RMSE of $\$ 344.51$ and MAPE of $8.06 \%$. The decision tree method again is the weakest predictive model that accounts for only $84.28 \%$ of the variances in public property prices, and with RMSE of $\$ 365.86$ and MAPE of $8.82 \%$. The boosting model have the best predictive performance that accounts for $94.28 \%$ of the variance in public property prices, and with the smallest RMSE of $\$ 220.71$ and MAPE of 5.30\%. The results using the testing dataset again affirm that the boosting model is a superior model compared to the traditional MRA model and the decision tree model in predicting public (HDB) housing prices.

Figures 7 and 8 show the graphical plots of the three performance measures estimated based on 50 random iterations in the predictions of property prices. Figure 7(a), (b) and (c) show the distributions for the $\mathrm{R}^{2}$, RMSE and MAPE, respectively, for the private property prices; whereas Fig. 8(a), (b) and (c) show the corresponding distributions of the three predictive measures for the public housing prices. The results presented in the visual forms are consistent with those presented in Table 3. The results show that the boosting models have the highest $\mathrm{R}^{2}$, and the lowest RMSE and MAPE, which imply that the AI-based models produce the most accurate predictions on property prices in both private and public housing markets.

We run additional out-of-sample tests using the housing transactions in 2018, which are not included in the training dataset (from 1995 to 2017). We compare the out-of-sample predictions of the AI-AVM (boosting) model vis-a-vis the enhanced spatially-adjusted MRA model and the decision model; and plot the results of forecasting outcomes for the private housing and the public housing in Figs. 9 and 10, respectively. The results show the AI-AVM (boosting) model keep the predictive errors (red dots) within a very tight range of less than $25 \%$ for the private housing 
Fig. 7 Predictive Performance Tests for Private Housing Market. Note: By randomly splitting the private housing market data into a training dataset and a test dataset by the ratio of $9: 1$, the three performance measures are derived for the tree models (boosting, decision tree and MRA). The top figure is $\mathrm{R}^{2}$ graph, which measures variance of the dependent variable accounted for by the predictors; and the middle figure is the root mean squared error (RMSE) measure, and the bottom figure is the mean absolute percentage error (MAPE) measure

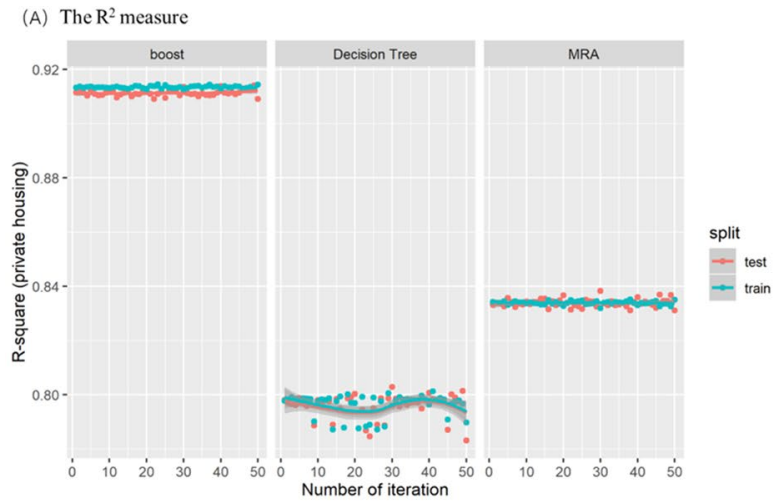

(B) The RMSE measure

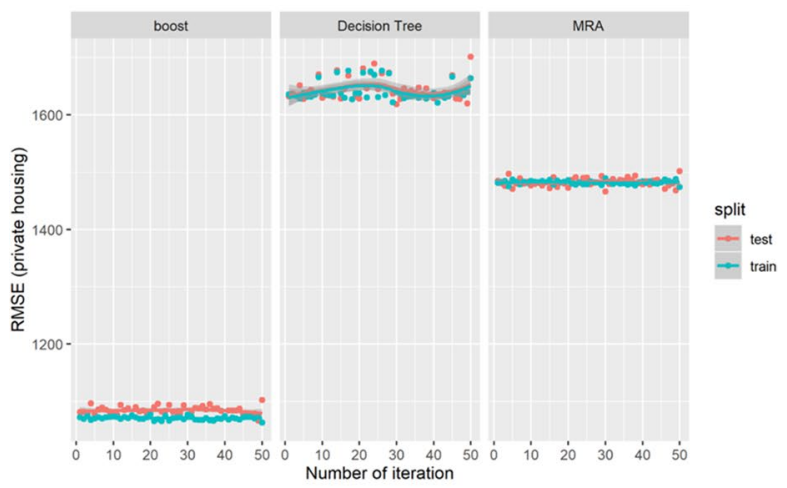

(C) The MAPE measure

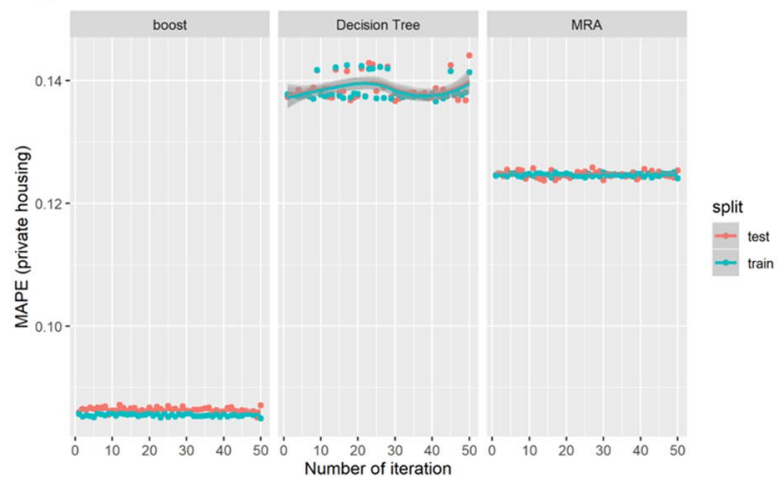

prices (with an average predictive error of $8.41 \%$ ) and $20 \%$ for the public housing prices (with an average predictive error of 5.62\%). The enhanced MRA model's performance improves after adjusting for spatial variations, ${ }^{5}$ but they still could not outperform the boosting model. The AI-AVM (boosting) model is still the most

\footnotetext{
5 The discussions of the spatially adjusted MRA is not within the scope of the current study, and the details are available in the paper by Agarwal, Fan, McMillen, and Sing (2020).
} 
Fig. 8 Predictive Performance Tests for Public Housing Market. Note: By randomly splitting the public housing market data into a training dataset and a test dataset by the ratio of $9: 1$, the three performance measures are derived for the tree models (boosting, decision tree and MRA). The top figure is $\mathrm{R}^{2}$ graph, which measures variance of the dependent variable accounted for by the predictors; and the middle figure is the root mean squared error (RMSE) measure, and the bottom figure is the mean absolute percentage error (MAPE) measure

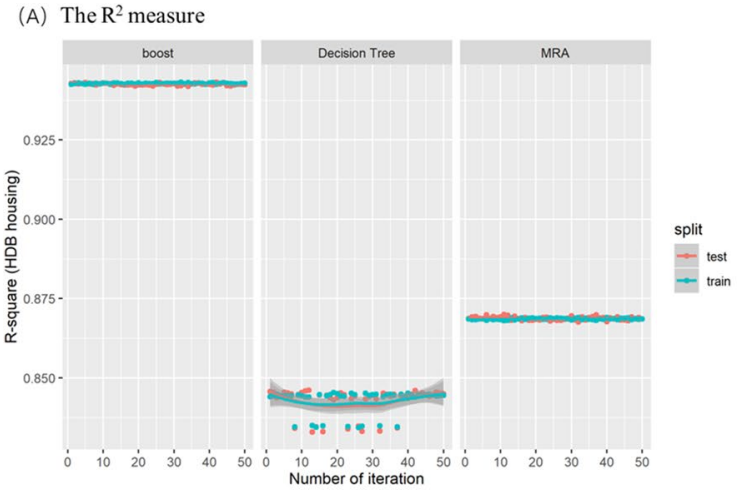

(B) The RMSE measure

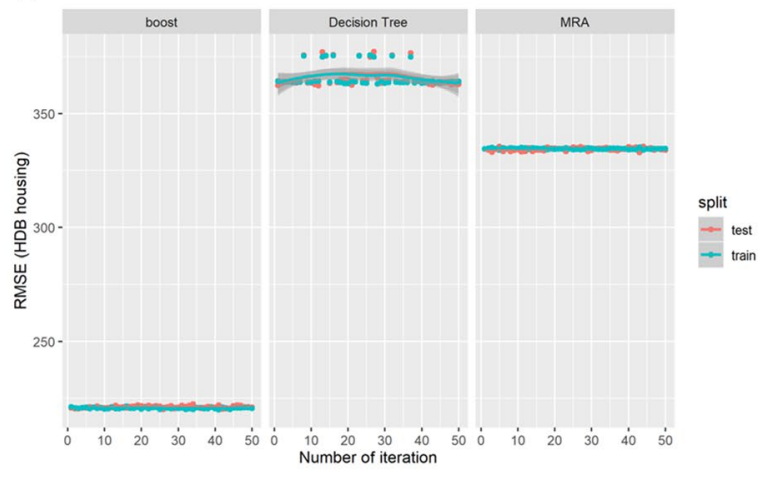

(C) The MAPE measure

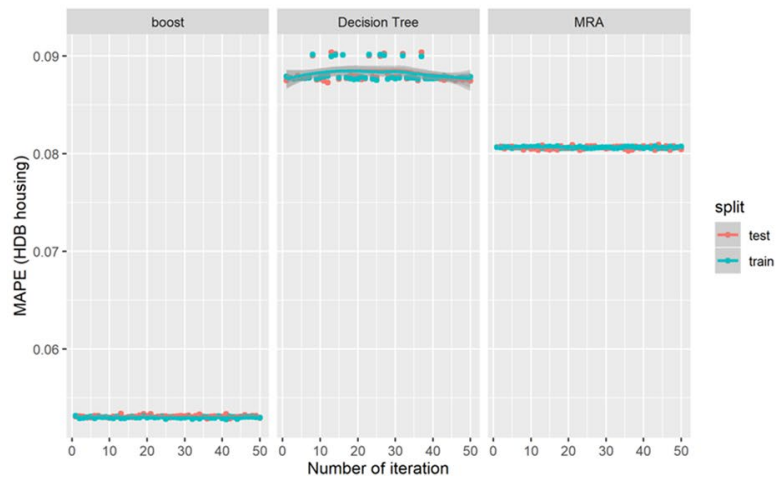

consistent and stable model in the predictions with relative tighter distributions of the predictive error terms.

\section{Potential Applications}

The industrial adoptions and applications of AI-AVM have been relatively slow in Singapore. The Housing and Development Board (HDB), the government's public housing agency, has introduced the AVM function in its "resale portal" to provide 


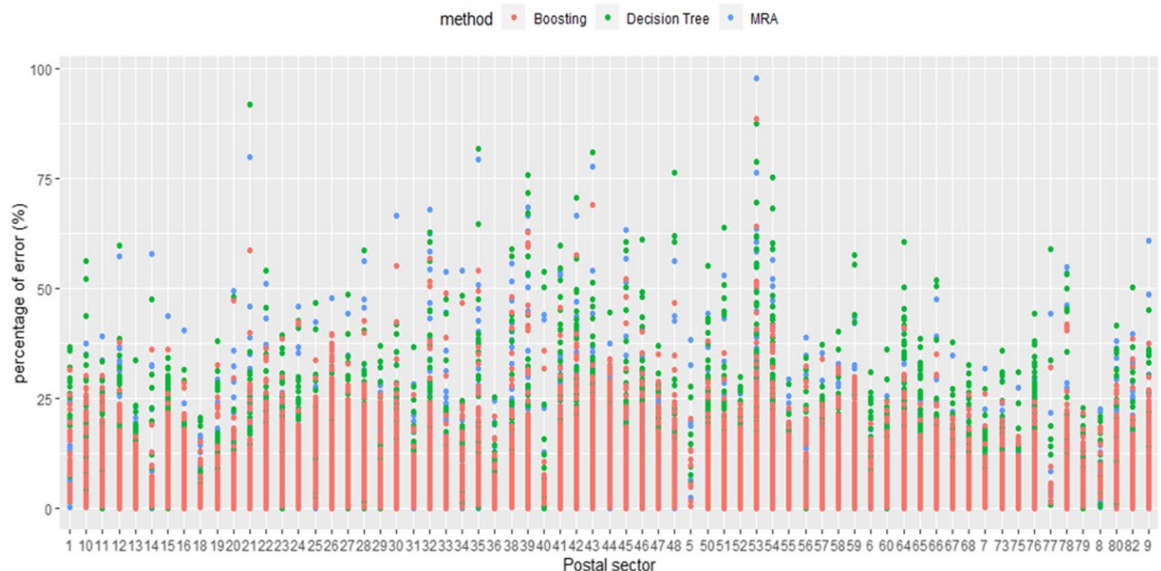

Fig. 9 Out-of-Sample Forecasting Tests for Private Housing Prices. Note: Using the housing transactions in 2018 as the out-of-sample datasets, the figures show the forecasting errors of the three model: boosting model, decision tree model and MRA model. The training dataset is based on the private housing transaction data from 1995 to 2017. The horizontal axis represents the postal sectors, which are based on the first two digits of the postal code in Singapore. The vertical axis represents the percentage error of the unit price estimations predicted the three models, respectively

method - Boosting - Decision Tree - MRA

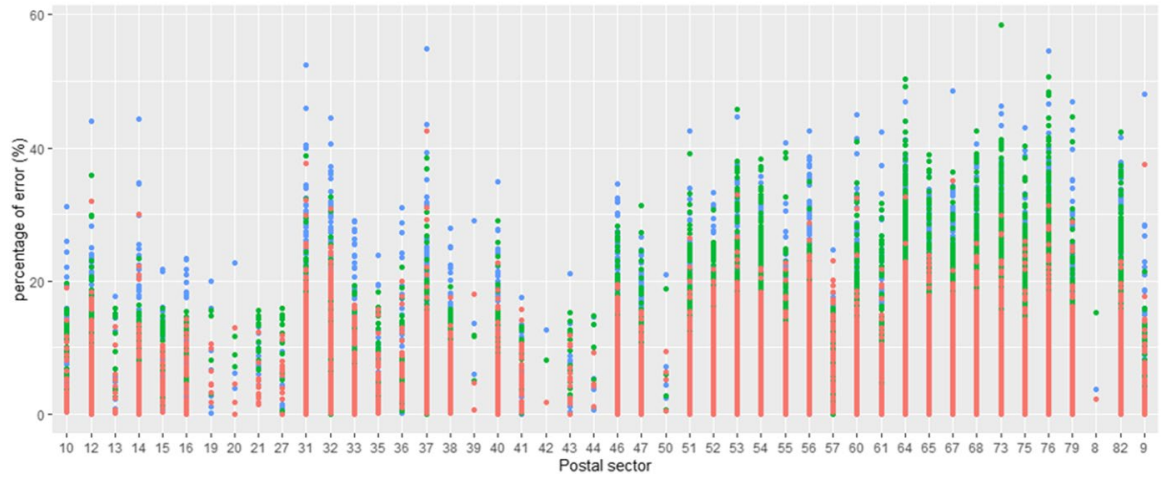

Fig. 10 Out-of-Sample Forecasting Tests for Public Housing Prices. Note: Using the housing transactions in 2018 as the out-of-sample datasets, the figures show the forecasting errors of the three model: boosting model, decision tree model and MRA model. The training dataset is based on the public housing transaction data from 1995 to 2017 . The horizontal axis represents the postal sectors, which are based on the first two digits of the postal code in Singapore. The vertical axis represents the percentage error of the unit price estimations predicted the three models, respectively

"indicative" values of resale public housing flats (Ibrahim et al., 2005). Some PropTech companies in Singapore have also strated exploring various applications of AVM in recent years.

In a recent study, Agarwal et al. (2020a, b) have demonstrated how AI-AVM models can be applied to estimate values for a large sample houses in Singapore. 
Table 4 Assessed Values for Public Housing Flats

\begin{tabular}{llllll}
\hline Variable & Symbol & Mean & Std. Dev. & Min & Max \\
\hline Unit Price (S\$/psm) & price & 3529.114 & 990.953 & 1919.020 & 5872.630 \\
Floor Level (storey) & floor & 7.405 & 3.989 & 1.000 & 30.000 \\
Unit Size (sqm) & area & 78.244 & 20.821 & 40.500 & 161.000 \\
Building age & age & 22.964 & 8.052 & 3.000 & 48.000 \\
Distance to MRT & dist_mrt & 6.229 & 3.358 & 0.200 & 31.790 \\
Distance to CBD & dist_city & 12.815 & 4.613 & 1.660 & 21.880 \\
\hline
\end{tabular}

Note: Based on a large sample of more than 800,000 public housing flat samples (nearly $80 \%$ of the full public housing stock in Singapore) as identified in the household database in Singapore, the AI-AVM boosting model is used to estimate the values of the public housing flats. The table generates the summary statistics for key features (including property and spatial attributes) of the public housing flats

Based on the data of a large sample on households and their housing addresses in Singapore, they track inter-generational housing mobility of Singaporean families. They showed that children born to the lower $60 \%$ percentile of the families by housing wealth moved up in their housing ladders relative to their parent generations. The inter-generational upward mobility is partly explained by the social engineering and the public housing programmes implemented in Singapore.

Based on the data obtained from a proprietary source that contain personal details and housing addresses for a large sample of Singaporean households living in public housing flats, we illustrate how the AI-AVM is applied to estimate the values of 816,544 public housing flats in Singapore. From the housing addresses and postal code, we are able to derive key property attributes, such as unit size, floor level (storey), building age, and spatial measures, such as distance to the nearest MRT station and distance to the CBD. With these inputs, we then apply the AI-AVM model trained earlier using the public housing resale dataset to automatically estimate the values for the sample of 816,544 public housing flats.

The summary statistics of the full sample of public housing flats estimated based on the proposed AI-AVM models are summarized in Table 4. The results show that the average unit value for public housing flat is estimated at $\mathrm{S} \$ 3529.11$ per square meter (psm). Based on an average unit size of 78.24 square meter, the average public housing value is estimated at $\mathbf{S} \$ 276,130.4$, as in the estimation date in 2019 . The average floor height of 7.4 storey indicates the high-rise and high-density nature of public housing in Singapore; and the average building age of the sample is 22.96.

Based on the estimated values, we created a 3-dimensional heat map of housing values in Fig. 11 (Agarwal, Fan, McMillen, \& Sing, 2020a). The value heat map shows prices are distributed spatially across the island with different peaks in selected neighbourhoods. Due to the deliberate public housing policies in Singapore to build new towns across the island, we do not see peak prices to be concentrated only in one location, and the prices are distributed quite widely and evenly across different parts of Singapore.

Based on the first 2-digit of the postal code, we sort the public housing flats by postal district and evaluate heterogeneity in unit prices across different neighbourhoods. The highest average housing values are found in the postal districts 21 


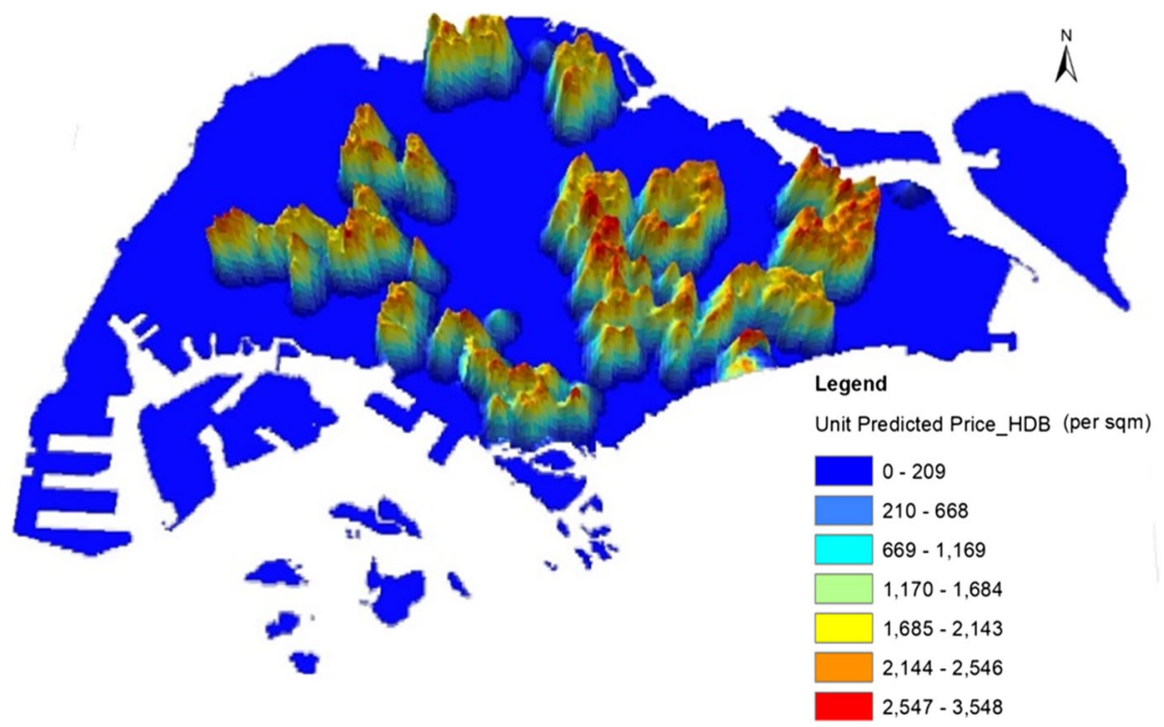

Fig. 11 3-Dimensional Housing Value Heatmap for Public Housing Flats in Singapore (Based on S\$ per square meter). Note: Based on a large sample of nearly 800,000 public housing flats in Singapore with the property and spatial attributes, the AI-AVM (boosting model) is used to assess the values of the flats as in 2019, and the map shows the heat-map of the assessed values, where the colour scheme represents price gradient in different location

(Little India, Farrer Park, Jalan Besar, Lavender), 10 (Telok Blangah, Harbourfront), 31 (Balestier, Toa Payoh, Serangoon) and 39 (Geylang, Eunos). The tallest public housing projects, Pinnacle @ Duxton, are built on a redeveloped site in District 10 . We also identify that the lowest average public housing values are found in postal districts 50 (Loyang, Changi), 26 (Bukit Timah, Holland Road), 73 (Kranji, Woodgrove, Woodlands), and 68 (Hillview, Dairy Farm, Bukit Panjang, Chao Chu Kang). The relatively low average public housing values in the District 26 area, which is the prime private residential area, is partly caused by limited supply of public housing flats in the area.

In Singapore, public housing flats cover nearly $80 \%$ of the total housing stock of nearly 1.37 million dwelling units of which approximately 1.08 units are public housing flats. For property tax assessment purposes, it would be challenging for the Inland Revenue Authority of Singapore (IRAS) to conduct regular review and re-assessment of the housing units every year. The proposed AI-AVM model could be used to help reduce bias and variance in assessed values, especially in areas where transactions are sparse.

\section{Conclusion}

This study develops the AI-AVM models based on the decision tree and boosting methods to predict the housing values in the private and public housing markets in Singapore. For the purpose of determining the prediction accuracy of the 
models, we conduct the "horserace" of the two AI-AVM models versus the traditional MRA model using the same set of real estate transaction data covering the period from 1995 to 2018.

The boosting model of the AI-AVM outperform the decision tree and the MRA model in the predicting tests for both the private and the public housing markets. The boosting model predict up to $91 \%$ of the variance in prices in the private market, and $94 \%$ in the public housing market, when using the testing dataset. Public housing units that have more homogenous property attributes relative to private housing units could explain the differential performance of the boosting models when applied predict prices in the two markets. Despite the differences, the errors of the boosting model is kept within a relative small MAPE of not more than $9 \%$ of the predicted housing values. The predictive test results show that the AI-boosting model, is a more superior model relative to the traditional MRA model in predicting housing values in both the private and the public housing markets in Singapore.

Although the models are developed based on the housing datasets in Singapore, the proposed AI-AVM models could be easily adapted and applied for automated valuations in other real estate markets. Compared to the earlier studies on AI-AVM, the study has two distinctive features in the AI applications to property valuations: First, the study uses the boosting method, which is a more robust and powerful algorithm relative to the conventional decision tree models. The model that allows for inter-dependence in the tree structure significantly improves the predictive power of the model; and Second, unlike the early studies that use a small sample data to train the AI models, this study train the model using more than 300,000 transaction data with a large set of variables on property and spatial attributes and time factors. The effects are apparent in term of generating smaller predictive errors and better out-of-sample forecasting performance.

We could further augment and expand the predictive powers of the proposed AI-AVM by exploring other algorithms such as random forest, etc. in the future study. Other extensions include using the AI-AVM to predict commercial property values, which are dependent on the future cash flows that are highly serially correlated; and to improve the computation efficiency of the model by using fuzzy definitions for selected property attributes in the models.

\section{Appendix}

\section{What is an Artificial Intelligence (AI) system?}

Artificial Neural Network (ANN) is an advance machine learning technique widely applied in pattern recognition in computation science and engineering fields. The development of ANN dated as far back to 1958, when Frank Rosenblatt (1958) introduced, for the first time, the perceptron, which is an algorithm for supervised learning of binary classifiers. The perceptron that can be trained to learn and recognize patterns seems promising, but the idea quickly fizzled off at 
the time in the fledgling AI community due partly to the lack of computing (Minsky \& Papert, 1969). The field of neural network research stagnated for many years, before the ANN saw the resurgence in the 1980s following the advancements in the parallel distributed processing system (Hopfield, 1982; McClelland \& Rumelhart, 1986, 1988).

ANN is one form of artificial intelligence model(s) that replicates the human brain's learning process. It consists of a set of nodes and a number of interconnected processing elements. A generic model of ANN comprises three different layers: input, hidden and output layers.

Likened a human brain, ANN is "a system of a massively distributed parallel processing that has a natural propensity for storing experiential knowledge" using mathematical algorithms (Gopal, 1998). There are many real-world applications in different fields, which include engineering, economics, computer science, finance, genetics, linguistics and psychology (Kryzanowski et al., 1993; Trippi \& Turban, 1993; Wong et al., 1992).

The ANN process starts with the entry of a large set of data at the "Input Layer"; then the machine is trained using the input information, and algorithms connecting various nodes are developed and tested through multiple iterations at the "Hidden Layer(s)"; and lastly, an output that is the estimated value of a property is calculated and generated the "Output Layer".

The standard MRA model is a popular statistical tool that has been used to develop various mass appraisal models. The MRA model has been proven to be highly robust when applied to homogenous properties, which have linear relationships between prices and other price determinants (Zurada et al., 2011). However, the MRA model does not have the ability to learn and recognise complexed patterns (Chaphalkar \& Sayali Sandbhor, 2013); and it lacks the ability to accurately predict property value with non-linear relationship.

ANN is a powerful tool, if undergone extensive training, can learn to produce non-linear solutions with generalisation ability (Nguyen \& Cripps, 2001; Hamazaoui and Perez (2011). A large set of high quality data is essential to develop and train the neurons of an ANN-based valuation model (Bogin \& Shui, 2020; Kok et al., 2017; Nguyen \& Cripps, 2001; Yacim \& Boshoff, 2018). Prior studies show that the ANN model is a superior forecasting model in accurately estimating "marginal prices associated with each characteristic of a property relative to the MRA models (Do \& Grudnitski, 1992; Tay \& Ho, 1992; Nguyen \& Cripps, 2001; Peterson \& Flanagan, 2009; Lai, 2011; Zurada et al., 2011; Tabales et al., 2013; Nguyen; V. T., 2014).

\section{References}

Agarwal, S. (2007). The impact of homeowners' housing wealth misestimation on consumption and saving decisions. Real Estate Economics, 35(2), 135-154.

Agarwal, S., Fan, Y., McMillen, D.P., \& Sing, T.F. (2020a). Tracking the pulse of a City - 3D real estate Price heat maps. Journal of Regional Science (forthcoming). 
Agarwal, S., Fan, Y., Qian, W., \& Sing, T. F. (2020b). Like father like son? Social engineering and intergenerational housing wealth mobility. Working paper, Institute of Real Estate and Urban Studies, National University of Singapore.

Agarwal, S., Song, C., \& Yao, V.W. (2017). Relational contracts, reputational concerns, and appraiser behavior: Evidence from the housing market, SSRN Working Paper.

Agarwal, S., Itzhak, B., \& Yao, V. (2015). Collateral valuation and borrower financial constraints: Evidence from the residential real estate market. Management Science, 61(9), 2220-2240.

Bogin, A. N., \& Shui, J. (2020). Appraisal accuracy and automated valuation models in rural areas. Journal of Real Estate Finance and Economics, 60, 40-52.

Case, K. E., \& Shiller, R. J. (1989). The efficiency of the market for single-family houses. American Economic Review, 79(1), 125-137.

Case, K. E., \& Shiller, R. J. (1990). Forecasting prices and excess return in the housing market. AREUEA Journal, 18(3), 253-273.

Chiarazzo, V., Caggiani, L., \& Marinelli, M. (2014). A neural network based model for real estate Price estimation considering environmental quality of property location. Transportation Research Procedia, 3, 810-817.

Clapp, J. M. (2003). A semiparametric method for valuing residential locations: Application to automated valuation. Journal of Real Estate Finance and Economics, 27(3), 303-320.

Fisher, J. D. (2002). Real Time Valuation. Journal of Property Investment \& Finance, 20(3), $213-221$.

Fisher, J., Miles, M., \& Webb, R. (1999). How reliable are commercial property appraisals? Another look. Real Estate Finance, 16(3), 9-15.

Geltner, D. (1989). Estimating real Estate's systematic risk from aggregate level appraisal based returns. Real Estate Economics, 17(4), 463-481.

Geltner, D. (1991). Smoothing in appraisal-based returns. Journal of Real Estate Finance and Economics, 4(3), 327-345.

Gongzlez, M. A. S., \& Formoso, C. T. (2006). Mass appraisal with genetic fuzzy rule-based systems. Property Management, 24(1), 20-30.

Guan, J., Zurada, J., \& Levitan, A. S. (2008). An adaptive neuro-fuzzy inference system based approach to real estate property assessment. Journal of Real Estate Research, 30(4), 395-422.

Hopfield, J. J. (1982). Neural networks and physical systems with emergent collective computational abilities. Proceedings of the National Academy of Sciences, 79, 2554-2558.

Ibrahim, M. F., Cheng, F. J., \& Eng, K. H. (2005). Automated valuation model: An application to the public housing resale market in Singapore. Property Management, 23, 357-373.

James, G., Witten, D., Hastie, T., \& Tibshirani, R. (2013). An introduction to statistical learning with applications in $R$. Springer.

Kindt, A., \& Metzner, S. (2019). A systematization approach for automated valuation models (pp. 208236). Real Estate Finance.

Kok, N., Koponen, E., \& Martinez-Barbosa, C.A. (2017). Big data in real estate? From manual appraisal to automated valuation. Special real estate issue in the journal of portfolio management, 202-211

Kryzanowski, L., Galler, M., \& Wright, D. W. (1993). Using artificial neural networks to pick stocks. Financial Analyst Journal, 49(4), 21-27.

Lam, K. C., Yu, C. Y., \& Lam, K. Y. (2008). An artificial neural network and entropy model for residential property price forecasting in hong kong. Journal of Property Research, 25(4), 321-342. https:// doi.org/10.1080/09599910902837051

Lenk, M. M., Worzala, E. M., \& Silva, A. (1997). High-tech valuation: Should artificial neural networks bypass the human valuers? Journal of Property Valuation \& Investment, 15(1), 8-26.

McClelland, J. L., \& Rumelhart, D. E. (1986). Parallel distributed processing: Explorations in the microstructure of cognition, Vol (1): Foundation. MIT Press.

McClelland, J. L., \& Rumelhart, D. E. (1988). Explorations in parallel distributed processing: A handbook of models, programs, and exercises. MIT Press.

McCluskey, W., Deddis, W., Mannis, A., McBurney, D., \& Borst, R. (1997). Interactive application of computer assisted mass appraisal and geographic information systems. Journal of Property Valuation and Investment, 15(5), 448-465.

McGreal, S., Adair, A., McBurney, D., \& Patterson, D. (1998). Neural networks: The prediction of residential values. Journal of Property Valuation \& Investment, 16(1), 57-70.

Minsky, M., \& Papert, S. (1969). Perceptrons. MIT Press.

Nguyen, N., \& Cripps, A. (2001). Predicting housing value: A comparison of multiple regression analysis and artificial neural networks. Journal of Real Estate Research, 22(3), 313-336. 
O'Roarty, B., Patterson, D., McGreal, W. S., \& Adair, A. S. (1997). A case based reasoning approach to the selection of comparable evidence for retail rent determination. Expert Systems with Applications, 12(4), 417-428.

Pagourtzi, E., Assimakopoulos, V., \& Hatzichristos, T. (2003). Real estate appraisal: A review of valuation methods. Journal of Property Investment \& Finance, 21(4), 383-401.

Phang, S. Y. (2004). House prices and aggregate consumption: Do they move together? Evidence from Singapore. Journal of Housing Economics, 13, 101-119.

Peterson, S., \& Flanagan, A. B. (2009). Neural network hedonic pricing models in mass real estate appraisal. Journal of Real Estate Research, 31(2), 147-164.

Quan, D. C., \& Quigley, J. M. (1991). Price formation and the appraisal function in real estate markets. The Journal of Real Estate Finance and Economics, 4(2), 127-147.

Rosenblatt, F. (1958). The perceptron: A probabilistic mnodel for information storage and organization in the brain. Psychological Review, 65, 386-408.

Ruppert, D. (2004). The elements of statistical learning: Data mining, inference, and prediction. Publications of the American Statistical Association, 99(466), 1.

Sing, T.F., Ho, K.H.D., \& Tay, P.H. (2002). A fuzzy discounted cash flow analysis for real estate investment, in Wang, $\mathrm{K}$ and Wolverton, Marvin L. (editors), real estate valuation theory.

Sing, T. F., Tsai, I. C., \& Chen, M. C. (2006). Price dynamics in public and private housing Markets in Singapore. Journal of Housing Economics, 15, 305-320.

Shiller, R. J., \& Weiss, A. N. (1999). Evaluating real estate valuation systems. Journal of Real Estate Finance and Economics, 18(2), 147-161.

Tay, D. P. H., \& Ho, D. K. H. (1992). Artificial intelligence and the mass appraisal of residential apartments. Journal of Property Valuation and Investment, 10(2), 525-539.

Trippi, R. R., \& Turban, E. (1993). Neural networks in finance and investing. Probus Publishing.

Tsukuda, J., \& Baba, S. I. (1994). Predicting Japanese corporate bankruptcy in terms of financial data using neural networks. Computers \& Industrial Engineering, 27(1-4), 445-448.

Wong, F. S., Wang, P. Z., Goh, T. H., \& Quek, B. K. (1992). Fuzzy neural systems for stock selection. Financial Analyst Journal, 48(1), 47-52.

Worzala, E., Lenk, M., \& Silva, A. (1995). An exploration of neural networks and its application to real estate valuation. Journal of Real Estate Research, 10(2), 185-201.

Yacim, J. A., \& Boshoff, D. G. B. (2018). Impact of artificial neutral networks training algorithms on accurate prediction of property values. Journal of Real Estate Research, 40(3), 375-418.

Zurada, J., Levitan, A. S., \& Guan, J. (2011). A comparison of regression and artificial intelligence methods in a mass appraisal; context. Journal of Real Estate Research, 33(3), 349-387.

Publisher's Note Springer Nature remains neutral with regard to jurisdictional claims in published maps and institutional affiliations. 